\title{
Low cost organic and inorganic sorbents to fight soil and water pollution
}

\author{
Avelino Núñez-Delgado ${ }^{1}$ (D) - Esperanza Álvarez-Rodríguez ${ }^{1}$ • María J. Fernández-Sanjurjo ${ }^{1}$
}

Received: 23 February 2019 / Accepted: 18 March 2019 / Published online: 30 March 2019

(C) Springer-Verlag GmbH Germany, part of Springer Nature 2019

In this editorial piece, the Guest Editors comment on the Special Issue (SI) of Environmental Science and Pollution Research "Low cost organic and inorganic sorbents to fight soil and water pollution."

Recycling waste materials and by-products is a main objective for environmental protection. In addition, soil and water pollution suppose global hazards that need to be controlled to avoid serious and increasing damages to public health and the environment as a whole. In this way, previous publications have commented on the promising field of recycling raw and modified waste and by-products to control pollution (NúñezDelgado et al. 2015). Also, related Special Issues have been previously published (for example, Elleuch et al. 2018; Higueras et al. 2019). However, the field of research is still open, and new findings would be welcome. This is the reason why the Special Issue was developed.

\section{Papers published in this Special Issue}

A total of 18 manuscripts were submitted to the SI. After review, 9 very interesting papers were accepted and published. Research teams from different countries worked on various aspects of the theme, covering the following items: adsorption of methylene blue on a variety of sorbent materials (Wang et al. 2018), the use of vegetal fibers and metal oxides for water decontamination (Kesraoui et al. 2018), Cu removal

Responsible editor: Philippe Garrigues

Avelino Núñez-Delgado

avelino.nunez@usc.es

1 Department of Soil Science and Agricultural Chemistry, Engineering Polytechnic School, University of Santiago de Compostela, Campus University, s/n 27002 Lugo, Spain by means of $\mathrm{KOH}$-modified pumpkin husk (Çelekli et al. 2018), or using a green adsorbent (Banerjee et al. 2018), P sorption on various waste and by-products (RomarGasalla et al. 2018), effects of organic amendments on plants subjected to Cd stress (Shahid et al. 2018), fluoride removal by means of raw or modified plant-derived carbons (Vilakati et al. 2018), waste mixtures used to remove a variety of organic pollutants (De-Toledo et al. 2018), and biochar as sorbent for volatile fuel organic compounds in water (Saiz-Rubio et al. 2018).

\section{Perspectives}

Since the last decades, this interesting field of research has been growing. In addition, previous special issues have focused on complementary aspects of the matter, some of them providing recent views and findings (for example, NúñezDelgado et al. 2018). As the generation of residues is increasing, it is expected that the need for developing new strategies, based on new data from research, will also continue to increase in the next years. In fact, the various aspects included in the theme can be considered public health and environmental issues of global relevance.

Acknowledgements The Guest Editors thank all authors and anonymous reviewers involved in this Special Issue, as well as the technical staff of Springer and of Environmental Science and Pollution Research working on it. Special thanks to Dr. Philippe Garrigues, as well as to Dr. Guilherme L. Dotto, Dr. Zhihong Xu, Dr. Elena Maestri and Dr. Tito Roberto Cadaval Jr., who carried out direct editorial tasks for the S.I.

\section{References}

Banerjee M, Basu RK, SKr D (2018) Cu(II) removal using green adsorbents: kinetic modeling and plant scale-up design. Environ Sci Pollut Res. https://doi.org/10.1007/s11356-018-1930-5 
Çelekli A, Bozkuş B, Bozkurt H (2018) Development of a new adsorbent from pumpkin husk by $\mathrm{KOH}$-modification to remove copper ions. Environ Sci Pollut Res. https://doi.org/10. 1007/s11356-017-1160-2

De-Toledo RA, Chao UH, Shen T, Lu Q, Li X, Shim H (2018) Development of hybrid processes for the removal of volatile organic compounds, plasticizer, and pharmaceutically active compound using sewage sludge, waste scrap tires, and wood chips as sorbents and microbial immobilization matrices. Environ Sci Pollut Res. https://doi.org/10.1007/s11356-018-2877-2

Elleuch B, Bouhamed F, Elloussaief M, Jaghbir M (2018) Environmental sustainability and pollution prevention. Environ Sci Pollut Res 25:18223-18225. https://doi.org/10. 1007/s11356-017-0619-5

Higueras PL, Sáez-Martínez FJ, Lefebvre G, Moilleron R (2019) Contaminated sites, waste management, and green chemistry: new challenges from monitoring to remediation. Environ Sci Pollut Res 26:3095-3099. https://doi.org/10.1007/s11356-018-3564-z

Kesraoui A, Bouzaabia S, Seffen M (2018) The combination of Luffa cylindrical fibers and metal oxides offers a highly performing hybrid fiber material in water decontamination. Environ Sci Pollut Res. https://doi.org/10.1007/s11356-018-1507-3

Núñez-Delgado A, Álvarez-Rodríguez E, Fernández-Sanjurjo MJ, Nóvoa-Muñoz JC, Arias-Estévez M, Fernández-Calviño D (2015) Perspectives on the use of by-products to treat soil and water pollution. Microporous Mesoporous Mater 210:199-201. https://doi.org/ 10.1016/j.micromeso.2015.02.001

Núñez-Delgado A, Nóvoa-Muñoz JC, Shaheen SM (2018) Editorial: New Findings on the Use of Biosorbents and Technically-Based Sorbents to Control Soil and Water Pollution. Front Chem 6(588). https://doi.org/10.3389/fchem.2018.00588

Romar-Gasalla A, Nóvoa-Muñoz JC, Arias-Estévez M, FernándezSanjurjo MJ, Álvarez-Rodríguez E, Núñez-Delgado A (2018) Controlling risks of $\mathrm{P}$ water pollution by sorption on soils, pyritic material, granitic material, and different by-products: effects of $\mathrm{pH}$ and incubation time. Environ Sci Pollut Res. https://doi.org/10. 1007/s11356-018-2267-9

Saiz-Rubio R, Balseiro-Romero M, Antelo J, Díez E, Fiol S, Macías F (2018) Biochar as low-cost sorbent of volatile fuel organic compounds: potential application to water remediation. Environ Sci Pollut Res. https://doi.org/10.1007/s11356-018-3798-9

Shahid M, Shamshad S, Farooq ABU, Rafiq M, Khalid S, Dumat C, Zhang Y, Hussain I, Niazi NK (2018) Comparative effect of organic amendments on physio-biochemical traits of young and old bean leaves grown under cadmium stress: a multivariate analysis. Environ Sci Pollut Res. https://doi.org/10.1007/ s11356-018-2689-4

Vilakati BR, Sivasankar V, Nxumalo EN, Mamba BB, Omine K, Msagati TAM (2018) Fluoride removal studies using virgin and Ti (IV)modified Musa paradisiaca (plantain pseudo-stem) carbons. Environ Sci Pollut Res. https://doi.org/10.1007/s11356-018-2691-x

Wang B, Gao B, Wan Y (2018) Comparative study of calcium alginate, ball-milled biochar, and their composites on aqueous methylene blue adsorption. Environ Sci Pollut Res. https://doi.org/10.1007/ s11356-018-1497-1

Publisher's note Springer Nature remains neutral with regard to jurisdictional claims in published maps and institutional affiliations.

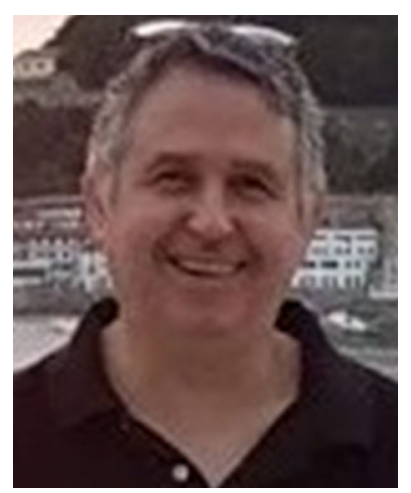

Dr. Avelino Núñez-Delgado Teacher-Researcher at the Department of Soil Science and Agricultural Chemistry, Engineering Polytechnic School, University of Santiago de Compostela, campus univ. Lugo, Spain. My PhD Thesis focused on diffuse pollution. Several books, book chapters and publications in Q1 research journals were carried out as a result. At the same time, I carried out research on wastewater treatment plants, and on designs of complementary wastewater treatment systems. Later on, I worked on biomarkers of water pollution in France. Back in Spain, my research focused on recycling, studying red mud as a sorbent material, sewage sludge, wood ash, and other kinds of waste and by-products, as well as different mixtures of them. I studied retention/inactivation of biotic and abiotic contaminants, and potential for agronomic recycling of these and other wastes. Special cases were those focused on composting. My research group registered up to 8 patents in relation to all these lines of research. Several recognitions, awards, publications, and $\mathrm{PhD}$ Thesis, resulted from these works. After that, my research focused mainly on retention of pollutants, using by-products to reach this end, facilitating recycling of these materials. Derived from that, my research team has published more than 50 papers in top journals (most Q1 in the JCR) since 2012, as well as many other works in proceedings, $\mathrm{PhD}$ Thesis, and book chapters.

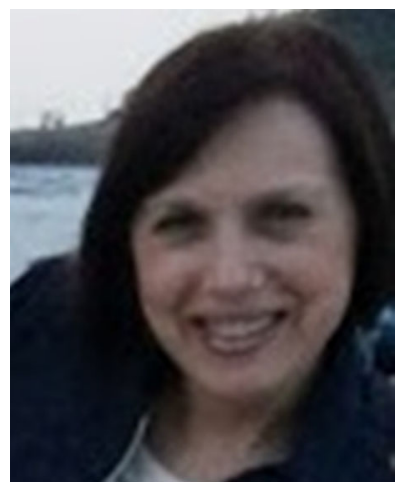

Dr. Esperanza Álvarez Rodríguez Full Professor of Soil Science, at the Engineering Polytechnic School, University of Santiago de Compostela (USC), Spain. She graduated in Biological Sciences at the University of Santiago de Compostela, where she also obtained her doctorate. Her research interest has been focused on environmental problems in relation to restoration of mine dumps, as well as on contamination by $\mathrm{F}$, As, heavy metals and antibiotics, and (bio)geochemistry of potentially toxic elements (particularly aluminum). In the last decade she studied different wastes from various agroforestry and industrial activities, and its potential use as fertilizers and bioadsorbents for heavy metals and antibiotics in contaminated soils and waters. She has authored more than 200 publications, 95 of them in JCR-referenced journals, and has presented more than 135 communications in national and international conferences. 


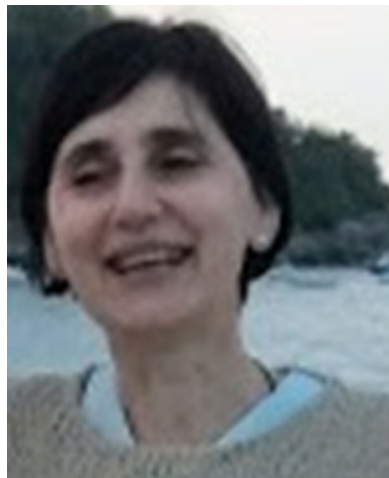

Dr. María J. Fernández-Sanjurjo Professor at the "Departamento de Edafoloxía e Quimica Agrícola" (Soil Science and Agricultural Chemistry), University of Santiago de Compostela, since 2001. She received a $\mathrm{PhD}$ in Biological Sciences from the University of Santiago de Compostela in 1994. She obtained a Marie Curie Grant Fellowship of the TMR Program (Training and Mobility of Researchers - European Community) and she carried out part of her research and teaching at the Universities of Florence (Italy), Le Marche (Italy) and the Centro Nazionale delle Ricerche-Florence (Italy). She was nominated for outstanding researcher by the Ministry of Education and Science (I3 Program-Government of Spain). Her recent research interest is focused on different fields: contamination by metals and antibiotics, adsorption and desorption processes of contaminants in soils and industrial waste, reuse of solid waste in the soil environment, soil fertility, and the study of rhizosphere soil in agroforestry systems and degraded media. She has participated in more than 50 research projects and more than 60 communications to Congresses and she is the author of more than 80 scientific articles included in the JCR index. 